Л И ТЕ Р А Т У А

1. Lippma a E., Pehk T., Past J., Eesti NSV TA Toim., Füüs.-Matem., 16, 345 (1967).

2. Levy G. C., Nelson G. L., Carbon-13 NMR for Organic Chemists, Wiley Interscience, 1972.

3. Le vy G. C., N els on G. L., J. Amer. Chem. Soc., 94, 4897 (1972).

4. Li p p ma E., P e h k T., Kemian Teollisuus, 24, 1001 (1967).

\author{
Ннститут химии \\ Академии наук Эстонской ССР \\ Поступила в редакцию \\ 1/III 1974
}

Ннститут кибернетики

Академии наук Эстонской ССР

\author{
EESTI NSV TEADUSTE AKADEEMIA TOIMETISED. 23. KOIDE \\ KEEMIA * GEOLOOGIA. 1974, NR. 3 \\ ИЗВЕСТИЯ АКАДЕМИИ НАУК ЭСТОНСКОИ ССР. ТОМ 23 \\ ХИМИЯ * ГЕОЛОГИЯ. 1974, № 3
}

удк $541.141 .8: 547.68$

ЛИа ПААЛЬМЕ, ОДетТ ПЕРЭН-РУССЕЛЬ, М. ГУБЕРГРИЦ, П. ЖАКИНЬОН

\title{
ФОТОДЕГРАДАЦИЯ НЕКОТОРЫХ МЕТИЛПРОИЗВОДНЫХ 3,4-БЕНЗПИРЕНА, РАСТВОРЕННЫХ В Н-ОКТАНЕ
}

Lia PAALME, Odette PERIN-ROUSSEL, M. GUBERGRITS, P. JACQUIGNON. MONEDE 3,4-BENSOPOREENI METOOLDERIVAATIDE FOTODEGRADATSIOON $n$-OKTAANIS

Lia PAALME, Odette PERIN-ROUSSEL, M, GOUBERGRITS, P. JACQUIGNON. PHOTODEGRADATION DES CERTAINS DERIVES METHYLES DU BENZO(3.4)PYRENE. SOLUTION EN n-OCTANE

В предыдущем сообщении [1] охарактеризована кинетика фотоинициированной деградации некоторых моно- и диметилпроизводных 3,4-бензпирена (БП), растворенных в бензоле. На последующем этапе исследования, результаты которого составляют предмет настоящей краткой публикации, аналогичный эксперимент был поставлен с тем же набором полициклических углеводородов (ПАУ) при неизменных условиях и методике проведения опытов (также в атмосфере аргона и кислорода [2]), но с использованием в качестве растворителя н-октана. Перечень производных БП, подавляющая часть которых была синтезирована в лаборатории органического синтеза Института химии природных соединений Национального центра научных исследований Франции, и их структура приведены в табл. 1.

Настоящее сообщение является первым плодом непосредственного научного сотрудничества французских и советских ученых в области изучения структуры и реакционной способности канцерогенных соединений.

Основные результаты исследования в первичной графической обработке приведены на рис. 1. Рассмотрение последнего показывает, что изменение во времени концентрации реагента происходит по линейному 
закону, что отвечает кажущемуся нулевому порядку суммарной реакции при расчете по убыли ПАУ. На этом основании по обычной методике определены значения константы скорости суммарной реакции $(k)$, квантового выхода (Ф) и константы деградации $\left(k^{\prime}\right)$ для изученных соединений, которые сопоставлены в табл. 2 с величиной энергии возбуждения молекул данного ПАУ в первое синглетное состояние $(0-0$ переход в спектре флуоресценции). Добавим, что опыты с III (табл. 1) проведены при пониженной концентрации реагента. Помещенные в
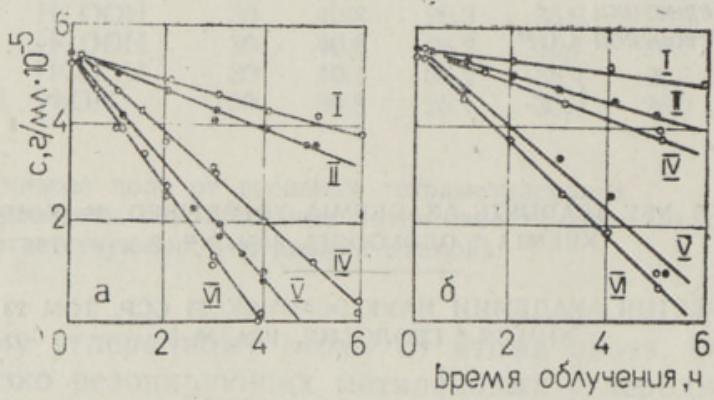

Рис. 1. Кинетические кривые фотодеградации метилпроизводных 3,4-бензпирена (см. табл. 1) в присутствии кислорода $(a)$ и в атмосфере аргона (б).

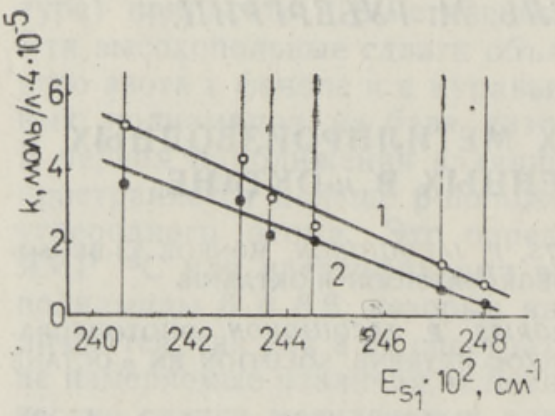

Рис. 2. Константа скорости фотодеградации в зависимости от $E_{s_{1}}$ в присутствии кислорода (I) и в атмосфере аргона (2).

табл. 2 в скобках значения $k$, приведенные концентрации $2,0 \cdot 10^{-4}$ моль/ $/$, получены в результате приближенного пересчета на основании установленной нами зависимости $k$ от $k^{\prime}$.

I 3,4-Бензпирен

11 1-Метил-3,4-бензпирен

III 6-Метил-3,4-бензпирен

IV 1,8-Диметил-3,4-бензпирен

V 5,10-Диметил-3,4-6ензпирен

VI 5,8-Диметил-3,4-бензирен
Таблица 1
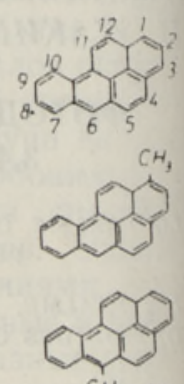

$\mathrm{CH}_{3} \mathrm{CH}_{3}$

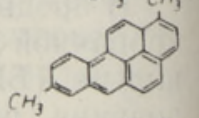

CH

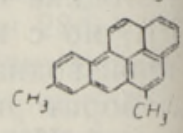

Анализ полученных данных показывает, что изменение природы растворителя (для которого область максимального поглощения в противоположность бензолу исключена из волнового диапазона применяемого УФ-излучения) не вызывает заметных качественных изменений макрокинетических закономерностей, управляющих процессом, но отражается на количественных его показателях. Так, все значения $\kappa$, Ф и $\kappa^{\prime}$ для системы, в которой растворителем служит бензол, как правило, оказыва- 


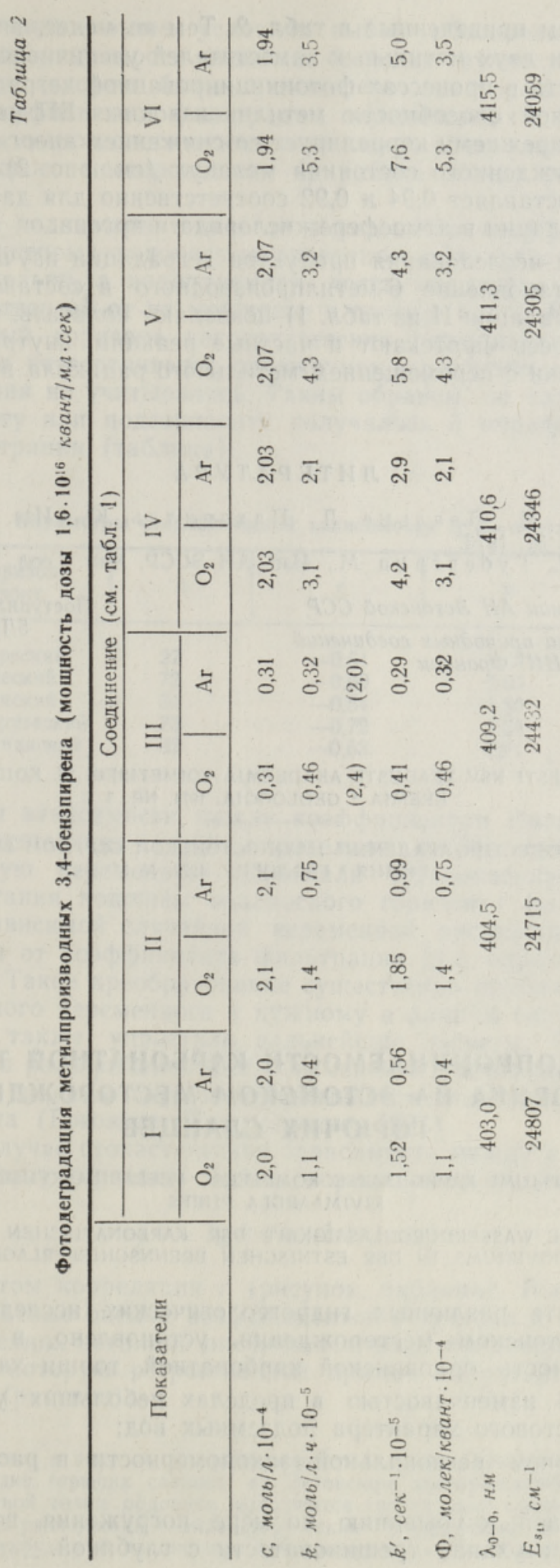


ются выше, чем приведенные в табл. 2. Тем не менее, ввод в молекулу БП одного или двух метильных заместителей увеличивает ее реакционную способность в процессах фотоинициированной деградации. Изменение реакционной способности метилпроизводных БП как функщии их структуры по-прежнему коррелирует со снижением энергии первого синглетного возбужденного состояния молекул (см. рис. 2). Коэффициент корреляции составляет 0,94 и 0,92 соответственно для данных, полученных при деградации в атмосфере кислорода и аргона.

Результаты исследования продуктов деградации изучаемых ПАУ (в частности, установление 6-метилпроизводного в составе реакционной смеси при деградации II из табл. 1) позволяют полагать, что в ходе суммарного процесса протекают и частные реакции внутримолекулярной перегруппировки с перемещением метильного радикала в молекуле производного БП.

\section{ЛИТЕ РА Т У Р А}

1. Губергрищ М., Паальме Л., Пахапилль Ю, Изв. АН ЭССР, Хим. Геол., 22. 31, 1973.

2. П а альме Л., Гу бергриц М., Изв. АН ЭССР, Хим. Геол., 20, 127, 1971.

Ннститут химии АН Эстонской ССР

Институт химии природных соединений НЦНИ Франции
Поступила в редакцию $5 /$ III 1974

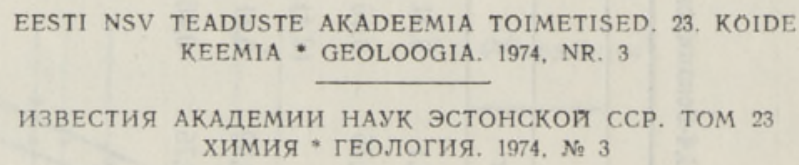

K. PHET

УДК $556.334 .4(474.2)$

\section{О ВОДОПРОНИЦАЕМОСТИ КАРБОНАТНОЙ ТОЛЩИ ОРДОВИКА НА ЭСТОНСКОМ МЕСТОРОЖДЕНИИ ГОРЮЧИХ СЛАНЦЕВ}

K. RIET, ORDOVIITSIUMI KARBONAATSE KOMPLEKSI VEELABILASKVUSEST EESTI POLEV. KIVIMAARDLA PIIRES

K. RIET. UBER DIE WASSERDURCHLĀSSIGKEIT DER KARBONATISCHEN SCHICHTENFOLGE DES ORDOVIZIUMS IN DER ESTNISCHEN BRENNSCHIEFERLAGERSTATTE

В результате различных гидрогеологических исследований, проведенных на Эстонском месторождении, установлено, в частности, что водопроницаемость ордовикской карбонатной толщи характеризуется:

1) крайней изменчивостью в пределах небольших участков ввиду трешинно-карстового характера подземных вод;

2) отсутствием региональной закономерности в распределении по площади;

3) тенденцией к убыванию по мере погружения водовмещающих пород ввиду затухания трещиноватости с глубиной. 